Brit. J. industr. Med., 1951, 8, 199.

\title{
THE WORK OF THE INTERNATIONAL LABOUR ORGANIZATION IN OCCUPATIONAL HEALTH
}

BY

\author{
A. GRUT
}

From the I.L.O., Geneva

The knowledge that certain occupations may lead to disease is probably as old as these occupations, but the first comprehensive effort in occupational medicine was made by Ramazzini in 1700 , and the active prevention of occupational diseases began much later.

Activities on an international scale were first instituted at the Congress of the International Working Men's Associations in 1867, and from 1890 various congresses dealt with protective regulations and legislation.

The Permanent International Commission for the Study of Industrial Diseases, founded in 1906, has organized nine international congresses in European cities. The conception of health protection through the united efforts of several countries was, therefore, not new when the International Labour Organization, established in accordance with the Treaty of Versailles, subsequently set up an Industrial Hygiene Division.

\section{Activities of the International Labour Organization}

The International Labour Organization is a specialized agency in relationship with the United Nations, and comprises the International Labour Conference, the Governing Body, and the International Labour Office.

The Conference, which meets annually, is composed of national representatives of government, management, and labour. This tripartite representation is an essential feature of the Organization. Its principal function is to formulate international labour standards in the form of Conventions and of Recommendations. It may also record its decisions in the form of resolutions. In addition to the general sessions, regional conferences are held.

The Member States are required to submit Conventions adopted by the Conference to their competent national authorities for possible ratification. If a country ratifies a Convention it is obliged to see that its own legislation is brought into accord with the Convention's provisions, and to report annually on the legislative measures which have been taken. Recommendations, on the other hand, are not subject to ratification, but States are obliged to consider them with a view to realizing their provisions by legislative or other action. Members of the Organization are required to report periodically on the position of their law and practice in relation to unratified Conventions and to Recommendations.

The Governing Body is also tripartite in its structure. Its functions include the framing of the Conference agenda, and the general supervision of the work of the Office, and of the various Committees of the Organization.

The International Labour Office provides the secretariat of the Conference ; it prepares documents concerning items on the agenda of the Conference and of the Governing Body, collects and distributes information, and on request furnishes technical assistance to governments, conducts such special investigations as may be ordered by the Conference or the Governing Body, and provides machinery for ensuring the effective application of Conventions. A number of committees and panels of experts have been set up under the Organization. There are, for example, eight committees, appointed since the last war, which deal with specific problems in different industries. These are called the Industrial Committees. Other I.L.O. bodies, which represent industries or occupations, are the Joint Maritime Commission, the Permanent Agricultural Committee, the Committee on Work on Plantations, and the Advisory Committee on Salaried Employees and Professional Workers. These committees, established on a tripartite basis, provide the Office with direct information about the problems in these various occupations, and at the meetings, practical measures for remedying unsatisfactory conditions can be discussed.

Recently a Joint Committee on Occupational 
Health has been established with the World Health Organization.

The International Labour Organization has collected data and documents concerning every aspect of occupational health; this information has been disseminated directly by correspondence or by publications ; international regulations in the form of Conventions have been established, and Recommendations and Resolutions have been made. International meetings of experts on special subjects have been convened in order to pool the available knowledge and to promote international research.

To assist the Office in these many functions, an expert advisory committee, called the Correspondence Committee on Industrial Hygiene, was established by the Governing Body in pursuance of a resolution of the First International Labour Conference. Subcommittees on Fatigue and on Silicosis have also been set up as the need arose. The members of these Committees are appointed by the Governing Body, and are chosen entirely on the basis of their technical knowledge. No attempt has been made to give representation to various interests on these committees.

\section{Information Service}

Direct Assistance.-This service has been given by correspondence in reply to requests from research workers, national organizations, and other persons or bodies dealing with occupational health.

The variety of these written requests for assistance received is indicated by the following list of answers sent out during the last two years to various countries : comments on industrial hygiene clauses in health codes to Costa Rica and to Turkey; advice on the text of an Industrial Hygiene Code to Iran ; a list of industrial hygiene authorities in various countries to Czechoslovakia ; information regarding the health of workers in various industries to Pakistan and to Uruguay; data on health of workers engaged in tunnelling to Italy; and the health of workers in water-front occupations to New Zealand ; data about the incidence of various occupational diseases, such as deafness, to Argentina, and cancer, to France ; a report on various hazards, such as those associated with the handling of cement, to Switzerland; the use of coated electrodes to Morocco, and of dangerous radiations to Italy and to the U.S.A. ; answers to questions about the toxicity of various chemicals have been sent to Egypt, the Netherlands, Switzerland, and the United Kingdom; and information about occupational health legislation in various industries has gone to Chile, Germany, Iran, Japan, Poland, and the United Kingdom. Data concerning various industrial hygiene methods and their application, such as dust suppression in the hemp industry, were sent to Tanganyika, and data concerning the use of colour in factories to Switzerland.

Publications.-A number of Office reports have contained information on occupational health.

Reports to the League of Nations.-Members of the Correspondence Committee have regularly contributed to the Year Book published by the Health Section of the League of Nations on the progress effected in occupational health. The Office prepared a study on the use of toxic substances in disinfestation in agriculture and horticulture, which was communicated to the League of Nations.

Reports to the-United Nations-A report to the United Nations on the activities of the Office is published yearly.

Reports for Conferences and Meetings of the I.L.O.- The contribution to the Director-General's report to the International Labour Conference describes the general trends in occupational health developments in the past year, and mentions special achievements and legislation.

In reports for Regional Conferences the trends in the specific region are described.

The establishment of the Industrial Committees facilitated contact with employers and workers in matters of occupational health. The Office has prepared studies on health conditions in the building, chemical, iron and steel, and textile industries, and in the metal trades.

Bibliography.-From the outset, all bibliographical references were indexed, and published in the International Labour Review until 1923, when the increasing volume necessitated separate publication in the Bibliography of Industrial Hygiene, which appeared quarterly from March, 1923, to September, 1939. Two additional numbers, published in 1944 and 1945, covered the publications up to 1941. This publication was resumed in 1948 under the title of Bibliography of Occupational Medicine, the first two numbers of which appeared yearly. From 1950 it was again published quarterly.

This publication lists each year about 4,000 titles of books and articles on occupational health. The titles are given in the original language. A translation into English and French is given of those titles not in English, French, Spanish, or Italian. The number of pages of each item indicates its volume, and a detailed system of headings gives the context of the articles.

A number of national periodicals give annotated bibliographies, but the number of items is small compared with the Bibliography, which is the only 
existing publication giving a comprehensive list of the year's publications on occupational health, grouped according to subjects, with cross references, and containing also a detailed subject index.

Technical Monographs: Studies and Reports, Series F.-Several of these publications resulted from studies undertaken in connexion with international regulations-five publications on the use of white lead in painting, two on anthrax. Four, the result of the international conferences on silicosis, included records of the conferences, a bibliography on pneumoconiosis, and an account of workmen's compensation for silicosis in the Union of South Africa, the United Kingdom, and Germany. Some monographs were prepared for meetings attended by the Office, and included for example, Industrial Hygiene and Safety and the International Labour Organisation; while others were reports of such meetings, for example, Medical Inspection of Labour, which reported the meeting of medical inspectors of factories in Düsseldorf in 1926.

The Encyclopedia Occupation and Health.The International Labour Conference held in Washington in 1919 requested the Office to establish a list of unhealthy industrial processes. In view of the constantly changing hazards in industry it was decided to publish an encyclopedia of occupational health, which was to interpret the words "unhealthy processes" on a broad basis, so as to include "toxic, infectious, parasitic, and all other causes likely to endanger or affect prejudicially the workers' health, life or morals". The material in this encyclopedia was to be grouped under (1) the work, (2) the worker, and (3) the place of work; and assistance in the preparation of the encyclopedia was to be sought from members of the Correspondence Committee, as well as from 95 external collaborators.

This encyclopedia of hygiene, pathology, and social welfare, entitled Occupation and Health, in two volumes totalling 2,300 pages, and comprising 410 articles, was published from 1930-34 in English and French.

The articles give technical descriptions of industrial processes, references to industrial uses, the causes of risks, pathology, clinical data, prophylaxis, statistics, and current legislation. Other articles deal with occupational diseases of the special systems, infections, etc., and finally there are comprehensive articles on environmental conditions, such as ventilation, heating, lighting, dust elimination, sanitation, etc. Supplements, published from 1938-40, contain articles on new processes or products, and revisions of earlier articles.
This publication describes industrial processes, whereas the usual textbooks are confined to descriptions of the diseases, or in the case of toxicologies, to descriptions of the toxic products. It gives the international aspect of the problem, thereby furnishing information which cannot easily be obtained elsewhere. It seems safe to say that the encyclopedia has been widely employed and, in spite of its age, is still used when the fundamental aspects of a problem are studied. It is now out of print, but a new edition is envisaged.

\section{International Meetings of Experts}

Meetings of Correspondence Committee.-Before the war, the Correspondence Committee on Industrial Hygiene held regular meetings to discuss reports on current problems prepared by the Office. The meetings passed resolutions which were either brought before the Governing Body, or were referred to the Office, or to special committees for further study. Questions to be treated by the International Labour Conference with a view to the establishment of international regulations (e.g., on workmen's compensation) were always discussed previously at one or more sessions of the Committee. To give an idea of the functions of this Committee, some of the subjects with which it has dealt are listed : medical inspection of factories (1924 and 1934) ; colour vision tests (1924) ; anthrax (1922-30 1934); colour vision tests (1924); anthrax (1922-30) ; industrial physiology (fatigue) (1926) ; injuries due to $x$-rays and radio-active substances (1926) ; frequency of periodical medical examinations (1926); hydrocyanic acid (1928, 1936); rationalization (1931) ; poisoning by solvents (1931 and 1933); nutrition in industry (1932 onwards) ; standard code of industrial hygiene $(1928,1933)$; employment of older workers (1933); manganese poisoning (1934); medical service in industry (1934) ; ocular service in industry (1934); standardization of radiographic methods in silicosis (1934) ; asbestosis (1935) ; infection from dust in the marketing and sorting of rags (1935); occupational dermatitis (1935); work in caissons (1935) ; labelling of containers of toxic substances (1934 and 1936) ; compensation for various occupational diseases (1926-36) ; miner's nystagmus (1936) ; ankylostomiasis (1936) ; disinfestation in agriculture and horticulture (1936); code for office work (1936) ; training in industrial medicine (1936); and statistics of occupational diseases (1936).

International Conferences of Experts.-Three International Conferences of Experts on Pneumoconiosis have been held, in Johannesburg (1930), in Geneva (1938), and in Sydney (1950). The two first 
conferences dealt mainly with silicosis. These Conferences have been of international importance in pooling the available information on the pathogenesis, clinical aspects, and diagnosis of pneumoconiosis and on the various preventive measures. The Conferences have also furthered national legislation on compensation for disability caused by pneumoconiosis.

The inscription of silicosis in the international schedule of compensatable diseases was a direct result of the Johannesburg Conference. The Sydney Conference discussed the incidence of pneumoconiosis in various countries, especially of coal miners' pneumoconiosis; the value of routine tests in determining disability; the diagnostic methods, especially in radiology, where a project for international classification of radiographs in some pneumoconioses was established; measures of treatment and rehabilitation, etc. The record of the Conference is now being prepared.

\section{International Regulations}

Several decisions of the International Labour Conference relate to aspects of occupational health : Recommendation on white phosphorus (1919); Convention on the use of white lead in painting (1921) ; Conventions on workmen's compensation (1925 and 1934); Recommendation on medical care (1944) ; Conventions on sickness insurance in industry and agriculture (1927); a number of Conventions, Recommendations, and Resolutions on the protection of women and young workers ; and a Convention and a Recommendation on labour inspection (1947).

In addition, the many Resolutions of the Correspondence Committee, approved by the Governing Body, dealt with'such subjects as duties of the factory doctor (1924) ; periodicity of medical examination (1926); medical inspection in factories (1934); protection against anthrax (1930) ; regulation of work in caissons (1935); compensation for various occupational diseases (1935); and the labelling of toxic substances (1935).

The protection of the health of workers in places of employment is on the agenda of the 1952 Session of the International Labour Conference, and may be the object of international regulations.

Lead Poisoning.-A Recommendation was adopted in 1919 whereby women and young persons should be excluded from various occupations involving exposure to lead, and that where employment of women and young persons was permitted, such employment should be subject to certain conditions dealing, inter alia, with ventilation, cleanliness of workrooms, notification of cases of poisoning, periodical medical examination, washing facilities, and special protective clothing.

The Convention on white lead adopted by the International Labour Conference in 1921 prohibited the use of white lead or sulphate of lead in internal painting, making its use subject to regulations. The employment of women and young persons in any painting work of an industrial character involving the use of these pigments was prohibited.

To facilitate the ratification of the Convention, the Office, in 1927, published a comprehensive account of the medical and technical aspects of lead poisoning and its prevention with gratifying results as to ratification. Twenty-seven countries have now ratified this Convention.

Phosphorus Poisoning.-In 1919 the Conference adopted the Recommendation that each Member State which had not already done so, should adhere to the International Labour Convention adopted at Berne in 1906 on the prohibition of the manufacture, importation, and sale of matches containing white phosphorus. At the present time, this Convention is in force in 34 States.

Anthrax.-The question of anthrax illustrates the difficulty of reaching international agreement on the practical application of preventive measures.

An international commission had studied the disinfection of hides and skins as early as 1908, and in 1919 the International Labour Conference adopted a Recommendation on disinfection of wool affected with anthrax spores. At that time this last question was being studied by a Committee appointed by the British Government, and a method was worked out, and put into operation on a commercial scale. However, when the question was discussed at the International Labour Conference in 1921, with a view to the adoption of a Convention, further study was considered necessary, and the question was referred to an Advisory Committee. This Committee was of the opinion that in most countries the principal danger of anthrax arose from the manipulation of hides and skins. A Mixed Subcommittee with the League of Nations was established, which directed research designed to discover effective methods of disinfection which would not injure the materials being handled.

In 1924 the International Labour Conference saw no prospect of arriving at an international agreement concerning the question of disinfection of wool and hair, and referred the other questions to the Correspondence Committee. As the research instigated by the Mixed Subcommittee had not, in 1928 , reached a stage at which the results could be applied industrially, and large-scale experiments in 
tanneries were impossible to effect with the means available, the Correspondence Committee proceeded to formulate Draft Regulations for Protection against Infection of Anthrax in the Hides and Skins Industry. These regulations, dealing with the hygiene of work places, personal hygiene of the workers, and notification of cases of anthrax, were approved by the Governing Body in 1931 .

In addition to the drafting of these regulations, progress was made by the publication of statistics on anthrax, by the furthering of veterinary control of infected flocks, and by contact with appropriate national organisations.

Medical Inspection of Factories.-The Factory Inspection Recommendation in 1919 advocated the establishment of a system of factory inspection including a service for safeguarding the health of the workers. The scope of inspection, the nature of the functions and powers of inspectors, and the organization of inspection, were elaborated in a Recommendation in 1923.

The Correspondence Committee in 1924 adopted a resolution defining the rights of medical inspectors ; in 1926 a resolution on the periodicity of inspections in various dangerous occupations; and, finally, in 1934, a resolution on the duties and requirements of the medical inspectors of factories.

The Convention in 1947 calls for measures to ensure that duly qualified technical experts and specialists, including specialists in medicine, are associated in the work of inspection. A Recommendation, also adopted in 1947, deals with labour inspection in mining and transport undertakings, and with the preventive duties of labour inspectorates in general to ensure protection against unhealthy or dangerous conditions.

Notification and Statistics.-The notification of occupational diseases is ensured by workmen's compensation laws. The Labour Inspection Convention, 1947, contains a provision concerning notification to the labour inspectorate of occupational diseases. It does not, however, establish an obligation on governments to require such notification, but states that the labour inspectorate shall be notified of cases of occupational diseases " in such cases and in such manner" as may be prescribed by national legislation. The same Convention requires the publication of statistics of occupational diseases in the annual report of the factory inspectorate as far as the matter is under the control of that authority. The Labour Inspection Recommendation, 1947, specifies details of such statistics, i.e., the number of cases and a classification according to cause and to industry.
The Seventh International Conference of Labour Statisticians, 1949, considered that the state of development of statistics on industrial injuries and occupational diseases did not justify the drafting of a Convention on the subject which will, however, be discussed at the 1952 session of the Conference.

Medical Training and Health Education.-The Correspondence Committee in 1934 adopted a resolution concerning the training of the personnel of medical inspection services.

In 1939, in a report on training the Office embodied all available data obtained by means of a questionnaire addressed to Member Governments.

The Joint Committee of the I.L.O. and the W.H.O. on Occupational Health, at its meeting in 1950, drew up recommendations on the training of medical students, doctors, nurses, industrial hygienists, and other persons responsible for the health of workers.

Medical Examination.-A Convention was adopted in 1922 concerning compulsory examination of children and young persons employed at sea. In 1946 two Conventions and a Recommendation were adopted concerning medical examination of young persons in industrial and non-industrial occupations, and a Convention on the medical examination of seafarers. The Conventions relating to industry require pre-employment medical examinations to determine physical fitness for employment, and provide for re-examinations until the age of 18 years or, in the case of occupations involving high health risks, until the age of 21 .

The Recommendation contains provisions for the treatment of persons found by examination to be suffering from disease.

Vocational Guidance.-A comprehensive Recommendation on vocational guidance was adopted by the Conference in 1949, advocating that appropriate tests of capacity and aptitude, and where so desired, other psychological tests, should be made available for use in vocational guidance as appropriate to the needs of individual cases. It also advocated the development, in cooperation with the appropriate rehabilitation services, of adequate and appropriate arrangements for the vocational guidance of young persons with physical or mental handicaps or limitations, or who manifest personality disorders of such a nature as to prevent, or make particularly difficult, their vocational adjustment.

Industrial Hygiene. - A Standard Code of Hygiene Regulations drafted by the Office was discussed at various meetings of the Correspondence Committee from 1928 onwards, and finally published in 1934. 
It contained minimum standards regarding factory construction, cubic space, ventilation, lighting, heating, underground premises, etc., and was intended for the guidance of countries revising or drafting for the first time their Labour or Hygiene Code.

A guide for factory inspectors in their work, Industrial Environment and Health, issued in 1936, described industrial hygiene methods.

A Model Code of Safety Regulations for Industrial Establishments, published 1949, contains regulations for dangerous and obnoxious substances, dangerous radiations, health protection, personal protective equipment, selection of workers and medical service.

Workmen's Compensation.-Two Conventions (1925 and 1934), and a Recommendation (1928) deal with workmen's compensation. The 1925 Convention contained the first international schedule comprising anthrax and poisoning by lead and by mercury; the second schedule increased the list considerably to a total of 10 diseases or hazards. These Conventions have been ratified by 32 and 22 countries, respectively. Since 1934, schedules in national legislation have superseded the international schedule considerably and a revision of this schedule is envisaged.

Rehabilitation.-Rehabilitation has been the subject of several Office publications, such as Training and Employment of Disabled Persons, Placement of Disabled Persons, Rehabilitation of Disabled Persons in the Mining Industry, and Rehabilitation of the Tuberculous.

Three Recommendations $(1948,1949,1950)$ deal with employment service organization, vocational guidance, and vocational training of the disabled, respectively.

\section{Collaboration with Other International Agencies}

Collaboration with the Health Section of the League of Nations comprised the exchange of information on venereal diseases, prevention of anthrax, occupational cancer, toxic substances in disinfestation in agriculture and horticulture, interchange of medical inspectors of factories, study of activities of medical services of insurance institutions, rural hygiene, and workers' nutrition.

Since 1948 close inter-secretariat collaboration has existed between the Office and the World Health Organization which has recently established a section on Social and Occupational Health. The joint Committee of the I.L.O. and W.H.O. on Occupational Health which has made recommendations on the training of persons responsible for the health of workers has also considered the col- laboration between industrial medical and public health services.

The Office has collaborated with the United Nations, the International Refugee Organisation, and the World Health Organization in planning the rehabilitation of disabled displaced persons, and a comprehensive scheme is now being developed for the rehabilitation of the disabled. Collaboration has been initiated with the F.A.O. in the planning of surveys of nutrition of workers in Latin America.

\section{Present and Future Activities}

The subject of the objectives and minimum standards of social security, including medical care, was on the agenda of the 1951 Conference, and will possibly be embodied in a Convention.

Revision of the Maternity Protection Convention is envisaged, and the steps to be taken to protect women workers, in view of their roles as mothers and home workers, are being studied by the Office.

Underground work of young persons in mines, which was dealt with in the Safety Code for Underground Work in Coal Mines, is being studied with the view to the drafting of international regulations.

The possibility of establishing international regulations for extending to agriculture the medical examination of young persons under 18 years is under consideration. The Office is also dealing with the following problems.

Recommendations of the Third International Conference of Experts on Pneumoconiosis.-A classification of radiographs in certain forms of pneumoconiosis was established at the Conference, and work on an international basis is progressing. This involves comparisons between the classification of identical radiographs examined by experts in various countries.

The Conference drew attention to the problem of preventing pneumoconiosis in civil engineering undertakings such as tunnelling, etc., and in the handling of grain cargoes, and the Office is studying measures against these hazards.

A directory of specialists in pneumoconiosis is in preparation. The Conference recommended that a future I.L.O. Conference should be held to deal with the prevention of pneumoconiosis mainly from the point of view of the engineer, the physicist, and the chemist.

Protection against Other Health Risks.-The agenda of the 1952 Conference contains the item : protection of the health of the workers in their places of employment.

The Office has prepared a report on the law and practice in various countries including notification, statistics, medical examination, inspection services, 
and engineering methods of protection. This report contains a questionnaire which will be circulated to the Member States, and a report based on the replies to this questionnaire will be discussed at the 1953 Conference, and may possibly form the basis of international regulations.

A revision of the international schedule for workmen's compensation is envisaged, as the 1934 schedule is outdated.

Studies on statistical information on the causes of diseases in the chemical industries, on the possibility of classifying chemical substances as dangerous, obnoxious and toxic, on the elaboration of a text on labels of containers of such substances, and finally, on the health of shift workers in the chemical industries, are in preparation for the next session of the Chemical Industries Committee.

The publication of the Bibliography of Occupational Medicine which was resumed in 1948 will be continued.

In addition to these activities of disseminating information and establishing international regulations, the Office provides direct advice and assistance, especially under the "Technical Assistance Programme for Under-developed Countries ".

\section{General Trends}

The scope of occupational health has changed during the time in which the I.L.O. has been active. The activities are at present not limited to prevention of hazards by prohibition or the drawing up of lists of such hazards, nor to payment of compensation for disablement. Occupational health aims at the promotion and maintenance of the highest degree of physical, mental, and social well-being of workers in all occupations.

The achievement of this aim needs action on a large scale: medical supervision of the workers by industrial health centres, provided with the necessary technical equipment, in collaboration with doctors familiar with local conditions. At present, the supervision of small work places, and of rural workers is grossly inadequate.

Legislative measures will probably be necessary, since voluntary health promotion is generally too slow and erratic.

An improvement of the training in occupational health of all those persons responsible for the health of the workers, will require a concerted action by universities, by government health services, and by employers and workers on a national and international scale.

There is still much to be learnt about adaptation to work through job analysis and medical examination of both the healthy and disabled. Industrial psychology has an important application in all relations between the worker and his job, his supervisor, his doctor and his manager, but the worker's greatest need is still a safe working environment.

Health surveys are easy to undertake in industrial populations, but should be undertaken only where a reasonable chance of positive results justifies the expenditure in time and money. All efforts should be mobilized in the pooling of knowledge, and a whole-hearted collaboration between individuals, groups, and nations should be achieved to maintain the productivity and well-being of the worker, for his well-being is one of the chief weapons against unrest and war. In this task the I.L.O. will continue as in the past, to collect and disseminate information on what is being done in the various countries, and to further the adoption of national, and where appropriate, international, measures to promote the health of all workers. 